\title{
Competency-Based Education in Medical Internship: Integrative Review
}

\author{
Leonardo Campos Teixeira ${ }^{1}$, Isabela Castilho Pellis² ${ }^{2}$ Émile Fernandes Spinassi Teixeira ${ }^{2}$, Rogério Saad Vaz ${ }^{3}$, Maria \\ Rosa Machado Prado ${ }^{3}$ \\ ${ }^{1}$ Family and Community Physician and teacher of Faculdades Pequeno Príncipe - Curitiba - Paraná, Brazil \\ ${ }^{2}$ Student of Medicine of the Faculdades Pequeno Príncipe - Curitiba - Paraná, Brazil \\ ${ }^{3}$ Research Professor of Faculdades Pequeno Príncipe - Curitiba - Paraná, Brazil \\ Correspondence: Maria Rosa Machado Prado, Faculdades Pequeno Príncipe, Avenida Iguaçu, 333 - Rebouças, Curitiba - \\ Paraná, Brazil.
}

\author{
Received: May 19, 2020 \\ Accepted: June 25, 2020 \\ Online Published: June 27, 2020 \\ doi:10.11114/jets.v8i7.4863 \\ URL: https://doi.org/10.11114/jets.v8i7.4863
}

\begin{abstract}
Medical education has undergone profound changes, currently, some medical courses are working competency-based education. This type of education is used in medical residences, however, at the medical internship, it is still not very used. Along with changes in teaching, assessments also had to adapt to contemplate the teaching-learning process. The present work aimed to review articles dealing with competency-based education in the medical internship since this area provides the medical student with the opportunity to experience the professional reality in practice. This is an integrative review study of published articles PubMed and BVS. After the search, the articles were filtered and a total of four publications addressing "internship", "competency" and "medicine. It was found that competency-based education still is something new and that is gradually being structured in the medical internship, so maybe there are few studies on this topic. Another important point evaluated in the analyzed articles, is the evaluation based on the period of 2015 to 2019 bases on skill and it was realized that it is also something that requires more research on this subject. It was concluded that competency-based education and how to evaluate it is a field that requires more research.
\end{abstract}

Keywords: medical education, medical internship, competency

\section{Introduction}

In 1949, Ralph Tyler, an educational psychologist, establishes some questions to address two educational programs of qualifying school or faculty. According to him, the educational institution should answer the following questions: which are the proposals of the educational program, which experiences must be offered to respond to these proposals, how to organize the program, and how to determine if the proposals are achieved (Tyler, 1949).

Since then, some scholars have thought about an outcome-based education. Benjamin Bloom created a taxonomy of educational objectives, including a cognitive domain (knowledge), a psychomotor (manual skills), and an affective (attitudes). In 1963, Carroll defended that the methods of teaching should differ among individuals since the acquisition of learning varies among students. In this way, an educational program should not be dimensioned by a specific time for all of them. Some need more and some need less time to achieve established objectives (Ten Cate, 2017; Bloom et al., 1956; Carroll, 1963).

One of the first courses of Medicine to apply these ideas of these students of education was Case Western Reserve University's Medical School in Cleveland, in 1950. Having Ralph Tyler as a consultant, it was created a

pre-clinical course, focused on basic sciences with clinical relevant objectives. Since the 1960s, several medical schools went foward this type of education, the Competency-Based Medical Education.

In 1978, McGaghie et al described CBME (Competency-Based Medical Education) in 3 characteristics: 1- organization of educational activities based on functions necessary for the practice of medicine in a given context; 2 - the principle that all students can achieve basic objectives pre-established; 3- the affirmation that the learning and its process can be tested empirically (Ten Cate, 2017).

It could be said that competence is the capacity to "mobilize, articulate and place in practice the necessary skills, abilities, and attitudes to perform the activities required in the context of work. It includes knowledge communication, 
technical skills, clinical reasoning, values, emotions, and reflections in daily clinical to the well-being of the individuals and community. Contrary to the traditional model of teaching, centered in learning objectives and knowledge, Competency-Based Medical Education is directed to outcomes and skills the learner can put in practice in the real context. Because of the centredness in the real context of practice, this type of education is considered extremely important for improving global health (Gruppen, Mangrulkar, Kolars, 2012).

Based on this concept, competency-based curricula have been developed in the most diverse areas. They consist of the systematization of the expected results of the student in their process of education in medicine (Costa et al., 2018). Two important initiatives in the field of Competency-Based Education in Family and Community Medicine residency are CanMEDS Family Medicine (Shaw, Oandasan, Fowler, et al., 2017), canadian, and The Family Medicine Milestone Project, american. Both seek to guide the education of residents in the specialties, each with its own characteristics.Although competency-based education has been widely used in medical residency as a guide for the training of medical specialists, it is still little used in medical school, specifically in medical internship.

In recent work, Sutton et al (Hamui-Sutton, 2019) make an interesting analysis of the evolution of medical education. According to the authors, there was an evolution in the way of thinking about learning in medicine, starting with the science-based curriculum, which divided the medical course into a 2-year basic cycle, a 2-year clinical cycle, and an internship. Elaborated by Flexner, in his famous report of the beginning of the century (10), it is still the hegemonic curricular model in medical courses.

In 1960, Problem-Based Learning (PBL) emerged, with curriculum integration around thematic fields using a more student-centered learning model. Towards the end of the twentieth century, Competence-Based Education emerges, guiding learning by the characteristics needed to perform required tasks. Finally, Entrustabel Professional Activities (EPAs) are created. These EPAs consist of controlled professional activities capable of mobilizing a range of skills to solve a complex real situation.

Due to all these pedagogical changes that occurred in the Medical Course throughout the twentieth and twenty-first centuries, there was a need for a change in the evaluation process as well. Just as education can be competence-based, so can assessment.

The present work aimed to review articles dealing with competency-based education in the medical internship, an area of crucial importance in the formation of physicians prepared to deal with contemporary complex issues involving the illness of individuals and communities.

\section{Method}

This is an integrative review study, whose objective is to synthesize in an orderly way the results approached by research on the subject in question, helping to deepen it. The integrative review is based on the elaboration of 6 steps: theme's identification and selection of the hypothesis to elaborate the integrative review, establishment of inclusion and exclusion criteria for the studies searched in the literature, definition of the information that will be extracted from the selected studies, evaluation of the studies. included in the interactive review, interpretation of results and, finally, presentation of the synthesis of knowledge (Mendes, et al., 2009).

To select articles that could be used in this integrative review, we searched the PubMed and BVS databases through the following descriptors internship, competency and medicine, and the "and" boolean between the descriptors, filtering articles that met all the descriptors. The study included articles published between 2015 and 2019, with available full text, main subject filtering as "professional competence", "teaching" and "educational assessment".

\section{Results}

In PubMed database, 44 articles were found, and after the application of the same filters were reduced to 15 articles, while in the BVS database, 261 articles were found, with reduction to 46 articles after the filter applications.

Of these 15 articles by PubMed and 46 articles by the BVS, their titles and abstracts were read, and as exclusion criteria, those who did not answer the research question or presented duplicates were excluded from the analysis, totalizing 4 articles, which were read in full, categorized and analyzed according to title, authors, journal, year of publication, method and results. The flowchart with the database search steps is shown in Figure 1, which was developed by the authors. Thus, from the categorization and analysis of the articles it was possible to interpret the results and perform a critical analysis on the subject. 


\section{PHASE 1}

Descriptors: internship and competences and medicine. PubMed: 44 publications BVS: 261 publications

\section{PHASE 3}

Exclusion criteria: didn't answer the research question or duplicate posts. PubMed: 2 publications BVS: 2 publications

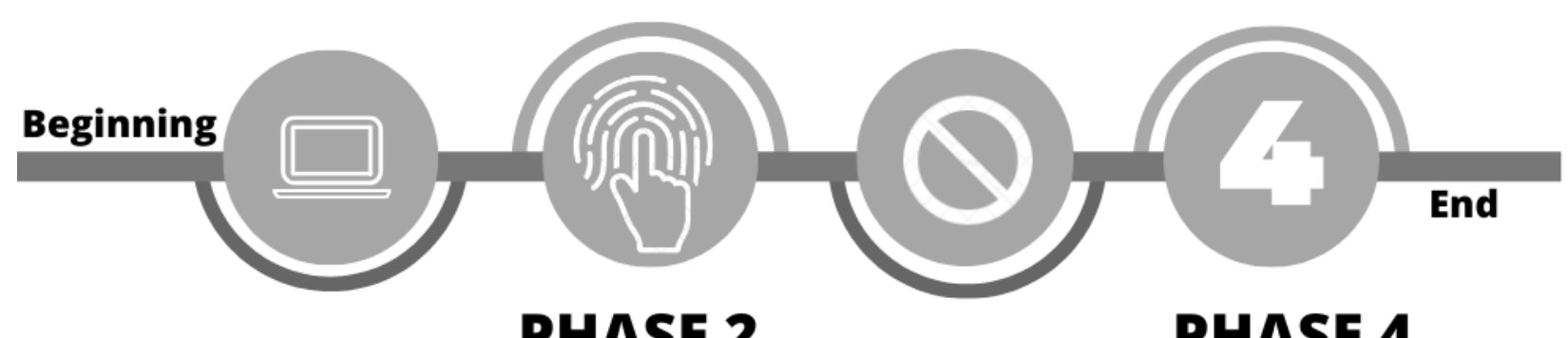

\section{PHASE 2}

Inclusion criteria: publications up

to 5 years old, available full text ,

filters of main subject as

"professional competence",

"teaching", and "educational

assessment".

PubMed: 15 publications

BVS: 46 publications
PHASE 4

Final sample: 4 publications

Figure 1. Flowchart with the database search steps.

The summary of the search results for the articles will be presented in the table 1 , where relevant information from selected publications was selected, such as: title, authors, journal and year of publication.

It is observed in table 1 the present informations, including methods and results of the analyzed articles, with the purpose of deepening the analysis of the themes presented in the publications and thus deepening on competence-based education. The results were divided into two categories to facilitate understanding what competency education is like during medical internship. The categories: Teaching Skills in the Medical Internship and Skills-based Assessment at Medical Internship. 
Table 1. Articles selected and analyzed for the integrative literature review and their content

\begin{tabular}{lllcl}
\hline \multicolumn{1}{c}{ Title } & Authors & Journal & Year & Method \\
\hline Teaching and & Cumming & Seminars & 2016 & $\begin{array}{l}\text { Review of } \\
\text { currently }\end{array}$ \\
assessing & s, L. C. & in & & $\begin{array}{l}\text { available } \\
\text { thics in the }\end{array}$ \\
newborn ICU & & Perinatolo & & gy \\
& & & & methods
\end{tabular}

$\begin{array}{llll}\begin{array}{l}\text { Understanding } \\ \text { Ethical }\end{array} & \begin{array}{l}\text { House et } \\ \text { al. }\end{array} & \begin{array}{l}\text { The } \\ \text { Journal of } \\ \text { Dilemmas in }\end{array} & 2014 \\ \text { the } & \begin{array}{l}\text { Emergenc } \\ \text { Cross-secti } \\ \text { onal study } \\ \text { design with }\end{array} \\ \text { Emergency } & & \text { Medicine } & \begin{array}{l}\text { qualitative } \\ \text { analysis }\end{array}\end{array}$

Department:

Views from

Medical

Students'

Essays

\begin{tabular}{|c|c|c|}
\hline $\begin{array}{l}\text { Teaching } \\
\text { competence at } \\
\text { the UNAM } \\
\text { Medical } \\
\text { Internship }\end{array}$ & $\begin{array}{l}\text { Martínez- } \\
\text { González } \\
\text { et al. }\end{array}$ & $\begin{array}{l}\text { Revista } \\
\text { medica del } \\
\text { Instituto } \\
\text { Mexicano } \\
\text { del Seguro } \\
\text { Social }\end{array}$ \\
\hline
\end{tabular}

\begin{tabular}{lll}
$\begin{array}{l}\text { Interprofe } \\
\text { ssional }\end{array}$ & Martínez- & BMC \\
assessment of & González & Medical \\
medical & & Education \\
students' & & \\
competences & & \\
with an & & \\
\hline
\end{tabular}

2017 Methodolo gical study for validation of an assessment instrument

2019 Cross-secti onal study with quantitativ e analysis
Results

There is a growing interest in ethics education and professionalism in neonatology, but evidence-based studies to determine the most effective methods are lacking. There is currently no standardized test to assess ethical knowledge in this area, although the research group is validating a tool for this potential use. 360-degree assessment is a tool that can assess a trainee's clinical competence in these areas using data and feedback from various key sources in a trainee's learning environment. An Individualized Learning Plan (ILP) should be used by all students and teachers to assist in the self-assessment and self-directed learning process, identifying strengths and weaknesses, formulating learning goals and tracking progress. An "inverted classroom" approach to this teaching can be effective (students learn from online material, and come to class to participate in activities such as group discussion and simulation). This model would engage students with various learning styles and allow mastery of knowledge and practical skills in ethics and professionalism during training.

In the 173 reflections among the portfolios analyzed, 10 themes were identified about ethical issues encountered during the Emergency Medicine rotation. Kappa statistics were performed to code 23 dissertations to ensure coding consistency and showed a high degree of agreement $(\mathrm{K}=0.83)$. The themes were two main domains: ethical conflicts, which included the 4 ethical principles (autonomy, social justice, nonmaleficence and beneficence), and aspirational virtues (faithfulness, respect, compassion, confidentiality and honesty). The reflections were mostly examples of how the ethical principle or virtue was not respected, or examples of aspirational behavior that the student admired and thought should be modeled. The most common themes were autonomy and social justice.

The authors evaluated the competencies of full professors of the Medical Internship of UNAM (Universidad Nacional Autónoma de México). The instrument used was the clinical OPINEST, created by several professionals with expertise in evaluation from the same university. The study described was the validation process of the questionnaire. The instrument has 54 items, each with 5 degrees of assessment (spectrum from never to always) according to the Likert scale. A total of 923 questionnaires were answered by the students of the UNAM Medical School internship for the evaluation of 81 full-time medical professors from the institution. As a result, the competency best evaluated after clustering the results was Clinical Problem Solving, with $81.7 \%$ of the answers "always" and "almost always". The worst rated was with "Evaluation", with $74.9 \%$ of "always" and "almost always".

Prediger et al. assessed attitudinal skills of medical interns at three German universities (Hamburg, Oldenburg and Munich) in a very creative way. Responsibility, teamwork, awareness of personal and attention-system limitations, ability to plan and prioritize, ability to deal with errors, use of scientific work method, and ability to communicate with 
instrument

suitable for

physicians and

nurses colleagues and supervisors were assessed through a 4-hour simulation in which the interns from these institutions were supposed to act as if they were on the first day of medical residency in a hospital. They were evaluated by medical supervisors, resident physicians and nurses, using 2 scales from 1 to 5: one to assess competence and another to measure the evaluator's confidence in the grade given. All classification groups showed consistent evaluation decisions ( $\alpha$ : Cronbach supervisors $=0.90$, residents $=0.80$, nurses $=0.78$ ) Nurses gave higher grades in all competencies and had more confidence in their judgment compared to supervisors and residents, and the difference in grade between the 3 groups was statistically significant.

\section{Discussion}

\subsection{Teaching Skills in the Medical Internship}

Teachers' competences are generally not properly studied and debated, with preference given to research in the area of education and student-based competency assessment. Martinez et al. (2017), in a very original study, showed the impressions of the students of the Medical Internship of a Mexican university about their teachers.

Using the Clinical OPINEST, a tool for assessing teachers' skills, they were able to determine the strengths and weaknesses of the Medical Internship teachers.

The results allow us some inferences. Firstly, the highest rated skill group was "Clinical Problem Solving," which encompasses several items related to teachers' technical skills, primarily related to proper diagnosis and treatment of disease. The other three competency groups (psychopedagogy, tutoring and assessment) were worse evaluated, allowing us to conclude about the predominance of technical knowledge in teacher education, leaving in the background very important features for the teaching practice.

Srinivasan and colleagues (2011), after extensive literature review and joint formulation of the necessary competencies for teachers engaged in medical education, came up with a final document containing 6 core competencies and 4 specialized teaching competencies. Only 1 of these 6 core competencies was Medical Knowledge, with the other 5 capabilities beyond the technical scope of the medical specialist. Learner-centredness, communication and interpersonal skills, professionalism, practice-based reflection and system-based practice in which the student is included, the other 5 core competencies, were considered equally important.

Carracio and colleagues (2016), defend some essential characteristics of physicians involved in Competency-Based Medical Education. According to the authors, this educational process should:

(a) Be based on the health needs of the population.

(b) Have learning outcomes focused on student needs rather than the traditional processes and structure of the educational institution.

(c) Meet the interests of all parties involved, such as health care, patients, students, teachers.

(d) Achieve competencies other than medical knowledge, such as communication, professionalism, advocacy, scholarship, leadership, and practice and system improvement.

(e) Empower students by making them active in their own learning process to progressively approach professional reality.

All these characteristics suggested by Carracio and colleagues (2016), require a medical professional with comprehensive knowledge and practice, different from the traditional one, focused only on medical knowledge and patient care. Although the professors of the aforementioned Mexican university present good results in all the mentioned competency domains, medical knowledge and patient care still prevail hierarchically superior to the other competencies.

\subsection{Skills-based Assessment at Medical Internship}

Data from this integrative review show that Competency-Based Education (CBE) and one of its components, Assessment, has been extensively studied around the world. In the area of Medical Education, although there are many articles on competencies in medical residency, the latu sensu postgraduate degree of excellence for doctors, there are few studies on medical internship. This period of intense practice and real training is very important to the future professionals as it is at this stage that the student really comes close to being a doctor. 
In view of the scarcity of work, the research article we found evaluates competencies on Medical Internship in a very interesting way. Prediger and colleagues (2019), assessed: (a) responsibility, (b) teamwork and collegiality, (c) knowing and maintaining own personal bounds and possibilities, (d) structure, work planning and priorities, (e) coping with mistakes, (f) scientifically and empirically grounded method of working, and (g) verbal communication with colleagues and supervisors. Due to the creativity of the method designed, the students were actually exposed to real situations that required all of these 7 competencies mentioned. The ability to perform multiprofessional tasks was studied, differently from what is usually worked, ie skills restricted to the work of the doctor.

Two very interesting points should be highlighted in this study. First, students were better evaluated by nurses than by residents and supervising physicians. Taking into account the objective of the paper, the assessment of competencies of medical internship students in interprofessional setting, this result was quite good, since the judgment of the physician's attitudinal practices will often be evaluated by nurses, physiotherapists, among others. One reason for the lower grade given by resident physicians and supervisors may be a better knowledge of the professional routine, which makes the assessment more detailed, more demanding.

In addition, the higher degree of certainty of nurses in the evaluation may be due to the greater custom of this professional to work interprofessionally. In nursing, the center of the work is the care of patients, which makes it essential to contact other professionals, who have essential skills to improve the health of people assisted. Although there is a tendency in medical schools to improve the look of the doctor, making him more holistic, that is, making him realize the needs of the person as a whole, most medical professionals still carry the bias of biomedical specialization (Baird et al., 2014). The inability of the physician to think through the entire care process may have increased the degree of uncertainty of the evaluators in this study.

The study cited raises an important question, that of interprofessional practice, essential for solving complex problems increasingly present in health services (Bridges et a.1, 2011). Due to the importance of this collaborative work, its insertion in education has increased.

We can define Interprofessional Education (IPE) as the interaction between students from two or more health professions involved in joint and reciprocal learning from existing real problems (BRIDGES et al, 2011). As in other areas of medical education, this has also been adapted to the Competency model, with reliable material establishing desirable learning outcomes in interprofessional health education (Schmitt et al., 2011; Thistletwaite et al., 2014).

\section{Conclusion}

Analysis of publications on competency-based education, over the past five years, showed lack of research on the topic in medical education Internship is a very important period in medical training, it is the time when the student will experience professional reality as the problems, decision making and relationship with patients and multidisciplinary team. Therefore, competency-based education It aims to promote education as a whole. When we look at what has already been published, we see the importance of this way of teaching and also to evaluate the teaching-learning process, which must contemplate knowledge, skill and attitude of students in the face of professional reality. It became very clear the need more research on the competency-based education and form of evaluation, because only then will it be possible understand the impacts on medical training.

\section{References}

Adrián Martínez-González, A., Lifshitz-Guinzberg, A., González-Quintanilla, A., María Monterrosas-Rojas, A., Flores-Hernández, F., Gatica-Lara, F., ... Sánchez-Mendiola, M. (2017). Teaching competence at the UNAM Medical Internship. Rev Med Inst Mex Insurance Soc. 55(6), 778-787. http://revistamedica.imss.gob.mx/editorial/index.php/revista_medica/article/view/1561

Almeida Filho, N. (2010). Reconhecer Flexner: inquérito sobre produção de mitos na educação médica no Brasil contemporâneo. Cadernos de Saúde Pública, 26(12), 2234-2249. https://dx.doi.org/10.1590/S0102-311X2010001200003

Baird, M., Blount, A., \& Brungard, S. (2014). The Working Party Group on Integrated Behavioral Healthcare. Joint principles: integrating behavioral health care into the patient-centered medical home. Ann Fam Med, 12(2), 183-185. https://doi.org/10.1370/afm.1633

Bloom, B. S., Engelhart, M. D., Furst, E. J., Hill, W. H., \& Krathwohl, D. R. (1956). Taxonomy of education objectives: the classification of educational goals; Handbook 1. New York, NY: Longmans, Green and Co.

Bridges, D. R., Davidson, R. A., Odegard, P. S., Maki, I. V., \& Tomkowiak, J. (2011). Interprofessional collaboration: three best practice models of interprofessional education. Medical Education, 16(1), 6035. https://doi.org/10.3402 /meo.v16i0. 6035 
Carraccio, C., Englander, R., Van Melle, E., Ten Cate, O., Lockyer, J., Chan, M. K., ... Snell, L. S. (2016). Advancing Competency-Based Medical Education: A Charter for Clinician - Educators. Academic Medicine, 91(5), 645-649. https://doi.org/10.1097/ACM.0000000000001048

Carroll, J. B. (1963). A Model of School Learning. Teachers College Record, 64(8), 723-733.

Costa, L. B., Esteche, F. E., Augusto Filho, R. F., Bomfim, A. L. B., \& Ribeiro, M. T. A. M. (2018). Competências e Atividades Profissionais Confiáveis: novos paradigmas na elaboração de uma Matriz Curricular para Residência em Medicina de Família e Comunidade. Revista Brasileira de Medicina de Família e Comunidade, 13(40), 1-11. https://doi.org/10.5712/rbmfc13(40)1632

Cummings, L. C. (2016). Teaching and assessing ethics in the newborn ICU. Seminars in Perinatology, 40(4), 261-269. https://doi.org/10.1053/j.semperi.2015.12.016

Gruppen, L. D., Mangrulkar, R. S., \& Kolars, J. C. (2012). The promise of competency-based education in the health professions for improving global health. Human Resources or Health, 10(43). https://doi.org/10.1186/1478-4491-10-43

Hamui-Sutton, A., Vives-Varela, T., Durán-Pérez, V. D., Gutiérrez-Barreto, S. E., \& Millán-Hernándes, M. (2019). Mapping an EPA-based comprehensive curricular proposal por UME. MedEdPublish. https://doi.org/10.15694/mep.2019.000186.1

House, J. B., Theyyunni, N., Barnosky, A. R., Fuhrel-Forbis, A. Seeyave, D. M., Ambs B., ... Santen, S. A. (2015). Understanding Ethical Dilemmas in the Emergency Department: Views from Medical Students' Essays. The Journal of Emergency Medicine, 48(4), 492-498. https://doi.org/10.1016/j.jemermed.2014.09.058

Mendes, K. D. S., Silveira, R. C. C. P., \& Galvão, C. M. (2009). Revisão integrativa: método de pesquisa para a incorporação na saúde e na enfermagem. Texto Contexto-Enfermagem, 17(4), 758-764. https://dx.doi.org/10.1590/S0104-07072008000400018

Prediger, S., Fürstenberg, S., Berberat, P. O., Kadmon, M., \& Harendza, S. (2019). Interprofessional assessment of medical students' competences with an instrument suitable for physicians and nurses. BMC Medical Education, 19(46). https://doi.org/10.1186/s12909-019-1473-6

Schmitt, M., Blue, A., Aschenbrener, C. A., \& Viggiano, T. R. (2011). Core Competencies for Interprofessional Collaborative Practice: Reforming Health Care by Transforming Health Professionals' Education. Academic Medicine, 86(11). https://doi: 10.1097/ACM.0b013e3182308e39

Shaw, E., Oandasan I., Fowler, N. (Eds). (2017). CanMEDS - FM: A competency framework for family physicians across the continuum. Mississauga, The College of Family Physicians of Canada.

Srinivasan M, Li S. T, Meyers, F. J., Pratt, D. D., Collins, J. B., Braddock, C., ... Hilty, D. M. (2011). Teaching as a Competency: Competencies for Medical Educators. Academic Medicine, 86(10), 1211-1220. https://doi.org/10.1097/ACM.0b013e31822c5b9a

Ten Cate, O. (2017). Competency-Based Postgraduate Medical Education: Past, Present and Future. GMS Journal for Medical Education, 34(5). https://doi.org/10.3205/zma001146

The Accreditation Council for Graduate Medical Education and The American Board of Family Medicine. (2013). The Family Medicine Milestone Project. Retrieved from http://faculty.washington.edu/pmford/milestonesAug2013.pdf.

Thistlethwaite, J. E., Forman, D., Matthewes, L. R., Rogers, G. D., Steketee, C., \& Yassine, T. (2014). Competencies and Frameworks in Interprofessional Education: A Comparative Analysis. Academic Medicine, 89(6), 869-875. https://doi.org/10.1097/ACM.0000000000000249

Tyler, R. W. (1949). Basic Principlees of Curriculum and Instruction. Chicago: University of Chicago Press.

\section{Copyrights}

Copyright for this article is retained by the author(s), with first publication rights granted to the journal.

This is an open-access article distributed under the terms and conditions of the Creative Commons Attribution license which permits unrestricted use, distribution, and reproduction in any medium, provided the original work is properly cited. 